REVISTA DE DERECHO UNED, NÚM. 18, 2016

\title{
DERECHOS DE LOS CONSUMIDORES \\ EN LA NUEVA LEY DEL SECTOR ELÉCTRICO 24/2013, DE 26 DE DICIEMBRE. ANÁLISIS CRÍTICO DE LA NUEVA REGULACIÓN
}

\author{
RIGHTS OF CONSUMERS IN THE NEW LAW \\ OF DE ELECTRICAL SECTOR: A CRITICAL VISION
}

\author{
JuAN Francisco García EgIDO \\ Letrado de la Administración de Justicia sustituto \\ Doctorando EEES Facultad de Derecho UNED \\ Programa de Doctorado en Derecho y Trabajo social. \\ Línea de Derecho civil ${ }^{1}$
}

Resumen: El tránsito de la tarifa integral al suministro plenamente liberalizado se hizo sin que los consumidores a la anterior tarifa de último recurso (TUR) suscribiesen un nuevo contrato adecuado a su situación; el régimen jurídico del consumidor doméstico no se adaptó a la nueva modalidad de suministro, resultando obsoleto; los derechos que la Directiva 2009/72/CE reconocía a los consumidores no se transpusieron íntegramente; y la vía administrativa de resolución de controversias entre consumidores y operadores presentaba notables carencias. Las presentes notas, pretende ofrecer una visión del actual del marco de los derechos de los consumidores y usuarios en la legislación sectorial desde una perspectiva crítica.

Abstract: The going on this integral rate to power liberal supply was made without the previous rate consumers (TUR) were signing a

\footnotetext{
${ }^{1}$ Agradezco a las Profesoras Bárbara de la Vega Justribó y Sonia Calaza López las observaciones y revisiones que han tenido que realizar a este primer trabajo de investigación sobre la materia de mi tesis doctoral.
} 
new contract adapted to their situation. The juridical regime of the domestic consumer was not adapted to the new modality to suply, it was absolete, the rights of the Directive 2009/72/CE which favoured consumers, they were not carried out enterely, the administrative route of resolution of controversies between consumers and operators have many gaps still exist. The present article aims to provide an actual visión of the protector rules of consumers in the legislation of the electrical sector and a critical assessment.

Palabras clave: Consumidor, energía, derechos.

Keywords: consumers, energy, rights.

Recepción original: 18/02/2016

Aceptación original: 6/04/2016

Sumario: I. Introducción; II. Nociones previas sobre energía y Sistema Eléctrico; III. Breve referencia a la evolución histórica de la electricidad en España. Normas aplicables al Sector Eléctrico; IV. Nueva regulación de los derechos de los consumidores domésticos de electricidad en la Ley 24/2013, de 26 de diciembre, del Sector Eléctrico. Normativa y sistema de precios: 1 . Concepto de Consumidor doméstico. 2. Derechos de los consumidores. 3. Régimen de precios en la nueva regulación; V. Novedades contractuales: 1. Contenido contractual regulado; 2 . Causas de rescisión y resolución, cláusula de penalización, en particular, el derecho de resolución unilateral del usuario acogido al PVPC, artículo 19.1.f). 3. Servicio gratuito de atención telefónica; 4. Mecanismo de corrección de errores en la facturación; 5. Duración de los contratos y prohibición de las cláusulas de permanencia. 6. Cambios de comercializador. VI. Reflexiones conclusivas: Análisis crítico de la reforma. Incidencia en los derechos de los denominados consumidores domésticos. 1. Carencias o deficiencias en la protección de los derechos del consumidor. 2. Mejoras en el nivel de protección al consumidor. VII. Bibliografía.

\section{INTRODUCCIÓN}

La Unión Europea impulsó la liberalización del suministro eléctrico con el fin último de crear un mercado interior de la energía plenamente competitivo. Este objetivo liberalizador debe ir acompañado de medidas que protejan al consumidor, y particularmente al doméstico.

En julio de 2009 fue suprimida la tarifa integral, paso decisivo para la liberalización del suministro eléctrico en España, en cumpli- 
miento de la normativa de la Unión Europea. Pero esa liberalización no vino acompañada de unas medidas adecuadas de protección al consumidor, así:

- No existe la transparencia exigida por los usuarios.

- Para los consumidores resulta muy difícil comprender los elementos que componen las tarifas eléctricas.

- Resulta desconocido a nivel general, hasta cuándo durará el déficit tarifario, se incluye en él algunos costes que no son aceptables por los consumidores y que inciden en el precio final de la energía y,

- los consumidores más vulnerables se encuentran desprotegidos.

En este trabajo, partiendo del concepto de energía, siguiendo la normativa que regula el Sector, dada por Ley del Sector Eléctrico 24/2013, de 26 de diciembre (en lo sucesivo Ley 24/2013) con los principales conceptos y novedades contractuales, estudiando su incidencia para el llamado consumidor doméstico.

El método utilizado para abordar el tema, ha sido, como no podía ser de otra manera, la consulta legal, lecturas de libros y bases de datos jurisprudenciales, que analizan, escasamente, los derechos e incidencia de la nueva normativa sectorial eléctrica en los derechos del consumidor de energía de esta clase considerado como persona física que usa la energía eléctrica para su consumo doméstico, excluidas las actividades comerciales o profesionales.

\section{NOCIONES BÁSICAS SOBRE ENERGÍA Y SISTEMA ELÉCTRICO}

No resulta fácil abordar el concepto de energía, algo tan simple que forma parte de nuestra vida cotidiana como es el acto de conectar el interruptor y, tan complejo, que permite que existan cambios en el mundo, calentamientos, enfriamientos y, en definitiva, vida y dinámica en el Universo. Así, una de las múltiples y variadas definiciones de energía, la que pueda englobar este fenómeno que explica la propia vida es la que concibe aquélla como la capacidad de un sistema para influir en su entorno ${ }^{2}$. Por ejemplo, una llama tiene más temperatura que su entorno y por eso calienta la porción del Universo que la rodea. Un sistema, un objeto que no se diferencie en nada de su entorno, no puede influir ni provocar ningún cambio en los demás objetos,

${ }^{2}$ Energía Eléctrica. Manual Básico para Juristas, La Ley, 1. ${ }^{a}$ Ed., 2014, p. 26.

(C) UNED. Revista de Derecho UNED, núm. 18, 2016 
cuerpos o sistemas que estén a su alrededor. Es un sistema incapaz de actuar, sin diferencia de energía respecto al entorno.

En física, la energía se define como la capacidad de un cuerpo o sustancia para realizar un trabajo. Atendiendo a aspectos tecnológicos y económicos, la energía es un recurso natural que adecuadamente manipulado y transformado es capaz de realizar una función, es decir, a su transformación se le puede dar un uso industrial y tener, por tanto, un sentido económico.

La energía como tal, ni se crea ni se destruye, sólo se transforma (Primer Principio de la Termodinámica). No obstante, el hecho de que las transformaciones empleadas no sean reversibles, provoca que la energía se degrade y que, a la postre, no sea posible extraer más trabajo del recurso natural del que se parte inicialmente (Segundo Principio de la Termodinámica). Toda trasformación del recurso natural para producir trabajo tiene un impacto, mayor o menor, sobre el medio ambiente. Aunque la energía del Universo sea constante, cada vez podemos usar menos proporción de esa energía total. La cantidad disponible de recursos naturales susceptibles de realizar trabajo es lo que se conoce como "recursos energéticos».

Hay que tener en cuenta que la energía eléctrica no se puede almacenar en grandes cantidades (obligando a generarla al mismo ritmo que se consume en cada instante) y necesita una continuidad eléctrica para su existencia. Esta continuidad es lo que define el circuito eléctrico y, si se interrumpe, la circulación de la corriente eléctrica se paraliza. Estas dos características hacen que la disponibilidad de esta energía, se logre mediante un sistema integrado por un elevado número de componentes, abarcando: generación de electricidad con diferentes energías primarias, transformación, líneas eléctricas de transporte y distribución, máquinas eléctricas, sistemas de protección, control y gestión, circuitos eléctricos dentro de las viviendas, comercios e industrias, etc., todos ellos interconectados entre sí, conformando lo que se ha denominado como «el Sistema Eléctrico»o también «la máquina más grande jamás construida por el hombre».

\section{BREVE REFERENCIA A LA EVOLUCIÓN HISTÓRICA DE LA ELECTRICIDAD EN ESPAÑA. NORMAS APLICABLES AL SECTOR ELÉCTRICO}

La primera referencia de la aplicación práctica de la electricidad en España data del año 1852, en el que el farmacéutico Domenech fue 
capaz de iluminar su botica en Barcelona ${ }^{3}$. En Madrid, ese mismo año, se hicieron pruebas de iluminación en la plaza de la Armería y en el Congreso de los Diputados. En 1875 una dinamo en Barcelona logró iluminar las Ramblas, la Boquería, el Castillo de Montjuic y parte de los altos de Gracia. A partir del año siguiente, comienza la electrificación industrial en España, constituyéndose en Barcelona la Sociedad Española de Electricidad, sociedad que figura como primera empresa eléctrica española (1881). Anteriormente, en 1858, se había publicado un Real Decreto que incluía como asignatura en los programas de estudios de la Escuela Superior de Ingenieros sobre la «aplicaciones de la electricidad y de la luz».

En 1875 se construye por Xifra i Dalmau la primera central eléctrica en España y en 1876 se fabrican las primeras máquinas Gramme en España. En 1885 se dicta un Decreto ordenador de las instalaciones eléctricas y, en 1888 una Real Orden reguladora del alumbrado eléctrico de los teatros españoles prohibiendo el de gas y autorizando las lámparas de aceite solo como sistema de emergencia.

En 1901, en la primera estadística oficial del sector eléctrico elaborada por los Ministerios de Fomento y Agricultura, constan 859 centrales eléctricas registradas y una potencia total de 127.940 caballos de vapor, siendo el 39\% de ellos de energía hidráulica. Años después, en 1909 fue construida la primera gran línea eléctrica para el transporte de electricidad con una longitud de $240 \mathrm{~km}$ entre el Salto del Molinar, en el río Júcar, a Madrid en una tensión de 66.000 voltios.

En el primer tercio del siglo XX fueron realizadas incontables inversiones en obras hidroeléctricas, constituyéndose nuevas empresas, cinco de ellas, llegan a controlar el $50 \%$ de la potencia instalada en 1930 y diez el 70\% del Sector. En el periodo de la guerra civil, 1936 a 1939, se interrumpe la expansión del Sector Eléctrico dada la precarización humana y económica, precisando España la importación de bienes de equipo necesarios para la industria agravado por el bloqueo económico internacional, acordado por Naciones Unidas. Ello motivó que el crecimiento de la potencia instalada fuera tan solo del 1,4\% anual en el periodo 1940 a 1944, agravándose la situación con el fenómeno de la gran sequía de los años 1944 y 1945 . No obstante, en el año 1944, UNESA integrada por 17 compañías que representaban el $80 \%$ de la producción del Sector, inicia la explotación unificada con la finalidad de abastecer las necesidades del país.

\footnotetext{
${ }^{3}$ Historia de la Energía en España. Manual de Energía y Sociedad Plataforma digitial, integrado en el Campus Iberdrola, en www.energíaysociedad.com consultado por última vez el 2 de marzo de 2016.
} 
Aprobado el sistema de Tarifas Tope Unificadas, entrando en vigor dos años después, en 1953, se unificaban así los precios de la electricidad en todo el territorio español. También fue constituida la Oficina Liquidadora de la Energía (OFILE) con el objeto de compensar los mayores costes que suponía esta forma de explotación.

Hasta mediados de la década de 1970, se construyen en España centrales hidroeléctricas y térmicas y entran en servicio las primeras centrales nucleares. En 1973 la potencia instalada superaba los $23.000 \mathrm{MW}$ y la red de transporte en tensiones superiores a $110 \mathrm{kV}$, tenía una longitud de más de $40.000 \mathrm{Km}$.

Por su parte, la crisis energética de 1973 supone el cambio de planteamiento en la política energética plasmándose en los llamados Planes Energéticos (PEN), el primero de ellos aprobado en 1975, impulsándose la construcción de centrales de carbón y nucleares.

La revisión del PEN en 1983 supuso la parada de cinco grupos nucleares en construcción, siendo definitivo con la Ley 40/1997.

En 1985 con la Red Eléctrica de España (REE), se produce la nacionalización de la red de transporte y la gestión del servicio público de explotación unificada del Sistema Eléctrico Nacional.

El Real Decreto 1538/1987 que entró en vigor el 1 de enero de 1988, denominado "Marco Legal Estable» supuso un cambio trascendente en la regulación del Sector Eléctrico con la finalidad de proporcionar un punto de referencia legal al sistema de ingresos de las empresas suministradoras de energía eléctrica y la determinación de la tarifa eléctrica en condiciones de mínimo coste. Las empresas eléctricas actuaban como gestoras de un servicio público de acuerdo con unas normas que fijaban sus ingresos.

En 1996 se firmó entre el Ministerio de Industria y Energía y las Empresas Eléctricas el «Protocolo para el establecimiento de una nueva regulación del sistema eléctrico nacional». Dicho protocolo establece las bases operativas del funcionamiento del sistema eléctrico mediante la liberalización del mercado y la introducción de un mayor grado de competencia.

La Ley 40/1997, de Ordenación del Sistema Eléctrico, cuyo objetivo era introducir la competencia en el sector, fue una ley que nunca entró en vigor pero supuso la creación de la Comisión Nacional del Sector Eléctrico como órgano independiente regulador de la actividad eléctrica y la titulización de la moratoria nuclear. 
Por su parte, la aprobación de la Ley 54/1997, del Sector Eléctrico, que supone trasponer la Directiva 96/92 CE al ordenamiento jurídico español, representa una transformación absoluta del sector eléctrico. Considera el carácter esencial del suministro eléctrico para el funcionamiento de nuestra sociedad, si bien ea diferencia de regulaciones anteriores, la presente Ley se asienta en el convencimiento de que garantizar el suministro eléctrico, su calidad y su coste no requiere de mas intervención estatal que la que la propia regulación especifica». Siguen reguladas las actividades de transporte y distribución, dada su característica de monopolios naturales, si bien son liberalizadas las actividades de generación y comercialización.

En el año 2003, con la aprobación de la Directiva 2003/54/CE, las instituciones europeas dieron un nuevo impulso a este proceso de liberalización del sector eléctrico. La Ley 17/2007, de 4 de julio, transpuso la citada Directiva a la legislación española. La modificación más relevante de la Ley 17/2007 es la eliminación de las tarifas integrales y a la introducción de la actividad de Suministro de Último Recurso el denominado Suministro de Referencia.

Los años 2012 y 2013 han sido de grandes cambios en el sector eléctrico: unas medidas han perseguido la reducción de costes del sistema (como las primas al régimen especial Real Decreto-ley 1/2012, y al resto de costes del sistema en el Real Decreto-ley 13/2012, Real Decreto-ley 20/2012, el Real Decreto-ley 2/2013 y el Real Decreto-ley 9/2013), la Ley 15/2012 sobre medidas fiscales a la actividad de generación de electricidad, persigue la recaudación de nuevos ingresos para el sistema. Normativa que trata de resolver el grave problema del déficit tarifario del sistema eléctrico español.

En cuanto al Real Decreto-ley 1/2012, suprime el procedimiento de inscripción en el registro de preasignación, y por tanto, los incentivos económicos para todas las instalaciones del régimen especial que no estuviesen inscritas en dicho registro. Además, suspende de forma indefinida los procedimientos de inscripción en el Registro de preasignación de retribución previstos en el Real Decreto-ley 6/2009 y en el Real Decreto 1578/2008 (para las instalaciones de energía solar fotovoltaica) y deja sin efecto la celebración de convocatorias de preasignación de retribución para los años 2012 y sucesivos.

El Real Decreto-ley 13/2012 de marzo de 2012 también es un paquete normativo relevante, que afecta a la totalidad de las actividades de la cadena energética: generación, transporte, distribución, comercialización y consumo, además de modificar algunas responsabilidades y aspectos relacionados con el funcionamiento o la retribución de 
organismos o agentes como la Comisión Nacional de Energía (CNE), el Instituto para la Diversificación y el Ahorro de la Energía (IDAE) o el Operador del Sistema Eléctrico. Impone nuevas medidas con el objetivo de disminuir los costes del sistema y la reducción del déficit tarifario a partir de 2013. El Real Decreto-ley 20/2012 por el que se aprueban diversas medidas para garantizar la estabilidad presupuestaria y de fomento de la competitividad.

Los Presupuestos Generales del Estado para 2013. La Ley 17/2013, el Gobierno introdujo dos medidas relativas al sector eléctrico: suspende para 2013 el mecanismo de compensación establecido para los costes insulares y extrapeninsulares, de modo que los costes de 2012 correrán a cargo de la tarifa eléctrica no siendo financiados con los presupuestos de 2013 y, establece que en las Leyes de Presupuestos Generales del Estado de cada año se destinará un importe a financiar el fomento de energías renovables, este importe será la suma de la estimación de la recaudación anual correspondiente al Estado derivada de los tributos incluidos en la Ley 15/2012 más el 90\% del ingreso estimado por la subasta de los derechos de emisión de gases de efecto invernadero, con un máximo de $450 \mathrm{M} €$. El 10\% restante, con un máximo de $50 \mathrm{M} €$, se afecta a la política de lucha contra el cambio climático.

El paquete regulatorio de diciembre de 2012 culmina con la aprobación del Real Decreto-ley 29/2012 de mejora de gestión y protección social en el Sistema Especial para empleados de hogar y otras medidas de carácter económica y social. 2013 comenzó también con nuevas medidas urgentes aprobadas por el gobierno mediante en el Real Decreto-ley 2/2013 de medidas urgentes en el Sistema Eléctrico y en el sector financiero, donde se establecen nuevos ajustes en costes del sector eléctrico.

El 13 de julio se publicó el Real Decreto-ley 9/2013, por el que se adoptan medidas urgentes para garantizar la estabilidad financiera del sistema eléctrico y que forma parte de un amplio paquete regulatorio cuyo fin principal es dotar de estabilidad financiera al sistema eléctrico.

La nueva Ley 24/2013 se publica como consecuencia de todos los cambios acontecidos en el sector desde 1997, la imposibilidad de garantizar el equilibrio financiero del sistema eléctrico y la reciente dispersión normativa. La Ley 24/2013 establece la regulación del sector eléctrico con la finalidad de garantizar el suministro de energía eléctrica y de adecuarlo a las necesidades en términos de seguridad, calidad, eficiencia, objetividad, transparencia y al mínimo coste para 
los consumidores. En 2013, se publica el Real Decreto 1047/2013 y el Real Decreto 1048/2013 por los que se establecen la metodología para el cálculo de la retribución de la actividad de transporte y distribución de energía eléctrica respectivamente.

Finalmente, la Ley 22/2013 de Presupuestos Generales del Estado para el año 2014 incluye las siguientes partidas para financiar los costes del sistema eléctrico: 903 millones de euros para atender al extracoste de generación procedente de los sistema extrapeninsulares, 2.907 millones de euros procedentes de la recaudación de los impuestos de la Ley 15/2012 de medidas fiscales para la sostenibilidad energética y 343,8 millones por el ingreso estimado por la subasta de los derechos de emisión de gases de efecto invernadero.

En junio de 2014, publicado el Real Decreto 413/2014 donde establece la metodología del régimen retributivo específico, de aplicación a las instalaciones de producción a partir de fuentes de energía renovables, cogeneración de alta eficiencia y residuos a las que les sea otorgado. Posteriormente se publicó la Orden IET/1045/2014, por la que se aprueban los parámetros retributivos de las instalaciones tipo aplicables a determinadas instalaciones de producción de energía eléctrica a partir de fuentes de energía renovables, cogeneración y residuos.

\section{NUEVA REGULACIÓN DE LOS DERECHOS DE LOS CONSUMIDORES DOMÉSTICOS DE ELECTRICIDAD EN LA LEY 24/2013, DE 26 DE DICIEMBRE, DEL SECTOR ELÉCTRICO. NORMATIVA Y SISTEMA DE PRECIOS}

\section{Concepto de consumidor doméstico}

La Ley 24/2013 define a los consumidores como las personas físicas o jurídicas que adquieren la energía para su propio consumo (art. 6.g Ley 24/2013) ${ }^{4}$. El objeto de estudio en este apartado es el consumidor persona física y, más concretamente, el llamado consumidor doméstico que la legislación española no define que debe entenderse por tal.

La Directiva 2009/72/CE sobre normas comunes para el mercado interior de la electricidad define al cliente doméstico como aquel que compra electricidad "para su consumo doméstico, excluidas las actividades comerciales o profesionales ${ }^{5}$. La Ley $24 / 2013$, si bien no incluye

\footnotetext{
${ }^{4}$ Véase el artículo 6 Ley 24/2013.

${ }^{5}$ Véase la Directiva 2009/72/CE.
} 
tal definición, prevé precios voluntarios para el «pequeño consumidor» (art. 43.2 Ley 24/2013); regula la resolución de reclamaciones de «usuarios finales que sean personas físicas» (art. 44 Ley 24/2013); permite aplicar el bono social a "personas físicas en su vivienda habitual» (art. 45 Ley 24/2013), y menciona la suspensión de suministros de «ámbito doméstico» (art. 52.4.i Ley 24/2013).

El término consumidor doméstico aparece en el preámbulo del Real Decreto-ley 13/2012, por el que se transponen directivas en materia de mercados interiores de electricidad y gas y en materia de comunicaciones electrónicas, y por el que se adoptan medidas para la corrección de las desviaciones por desajustes entre los costes e ingresos de los sectores eléctrico y gasista y, antes, en el Real Decreto 1955/2000, por el que se regulan las actividades de transporte, distribución, comercialización, suministro y procedimientos de autorización de instalaciones de energía eléctrica, en el artículo 110 ter, sobre contratos firmados por los clientes domésticos.

\section{Derechos de los consumidores}

La Ley 24/2013 dedica su título VIII a la regulación del régimen jurídico de los consumidores de energía eléctrica, manteniendo la regulación del precio mediante el llamado suministro de referencia, que comprende tanto el precio voluntario para el pequeño consumidor como el bono social.

La Ley 24/2013 introduce mejoras en la protección del consumidor doméstico incorporando un catálogo de derechos de los consumidores de energía eléctrica previsto en la Directiva 2009/72/CE y establece un sistema administrativo de resolución de controversias entre consumidores y operadores ante el Ministerio de Industria, Energía y Turismo, análogo al del sector de telecomunicaciones.

Así, la nueva ley regula los derechos y obligaciones de las empresas distribuidoras y comercializadoras, así como los derechos y obligaciones de los consumidores, remitiendo su desarrollo a un reglamento que podrá limitar estos derechos especialmente en caso de impago. Se difiere a un reglamento la regulación de las medidas de protección del consumidor, que a su vez tendrán que recogerse no en todos los contratos entre comercializador y consumidor, sino sólo en los de «aquellos consumidores que por sus características de consumo o condiciones de suministro requieran un tratamiento contractual específico» según establece el artículo 43.3 de la Ley 24/2013. Igualmente se difiere a la regulación reglamentaria cuestiones tan signifi- 
cativas para los usuarios como «los mecanismos de contratación y las condiciones de facturación de los suministros, incluyendo los procedimientos de cambio de suministrador y de resolución de reclamaciones», estableciendo una única limitación legal y es que estos cambios se realizarán en «un plazo máximo de 21 días» 6 .

En la nueva Ley regula el «autoconsumo» en su artículo noveno; reitera derechos ya reconocidos a los consumidores por la legislación anterior (derecho a ser asesorado en el momento de la contratación sobre el peaje de acceso y la potencia o potencias a contratar, derecho al cambio de suministrador en un plazo máximo de 21 días o el derecho a elegir el medio de pago entre los comúnmente utilizados en el tráfico, entre otros). Como novedad, reconoce expresamente el derecho a ser suministrados a unos precios fácil y claramente comparables, transparentes (factura desglosada y comprensible) y no discriminatorios ${ }^{7}$; obliga a disponer de un servicio de atención telefónica gratuita y a informar sobre los números geográficos asociados a números de tarificación compartid ${ }^{8}$ y establece un procedimiento administrativo y gratuito de resolución de reclamaciones ante el Ministerio de Industria, Energía y Turismo ${ }^{9}$. La resolución final podrá obligar a la restitución de lo cobrado indebidamente, así como a la indemnización de los daños ocasionados por la vulneración de derechos contemplados en la ley sectorial (ej. compensación por interrupción del servicio). Aunque la Comisión Nacional de los Mercados y la Competencia (CNMC) carece de competencia para resolver controversias contractuales con usuarios finales, sí se atribuye a este organismo la función de supervisar la efectividad y la aplicación de las medidas de protección a los consumidores, pudiendo «dictar resoluciones la efectividad pudiendo dictar resoluciones jurídicamente vinculantes tendentes al cumplimiento de las mismas» ${ }^{10}$.

\section{Régimen de precios en la nueva regulación}

La Ley 24/2013 introduce un nuevo régimen de precios minoristas regulados, distinguiendo entre los precios voluntarios para el pequeño consumidor (PVPC) y las tarifas de último recurso (TUR). Se prevé reglamentariamente la regulación de los requisitos que han de cum-

\footnotetext{
${ }^{6}$ Art. 43.3. Ley 24/2013.

${ }^{7}$ Arts. 44.1.d.8. ${ }^{\circ}$, letras e), j), n), de la Ley 24/2013.

${ }^{8}$ Arts. 44.1.o y 46.1 Ley 24/2013.

${ }^{9}$ Art. 43.5 Ley $24 / 2013$

${ }^{10}$ Art. 43.6 Ley 24/2013.
} 
plir los consumidores para acogerse a las diversas modalidades de precios regulados (PVPC, TUR o bono social).

El Reglamento a que se hace referencia por la Ley 24/2013, es el aprobado mediante Real Decreto 216/2014, de 28 de marzo, por el que se establece la metodología de cálculo de los precios voluntarios para el pequeño consumidor de energía eléctrica y su régimen jurídico de contratación $^{11}$. La principal novedad introducida por el RD 216/2014 es el nuevo sistema de determinación de los precios de la energía para los consumidores acogidos a PVPC.

En el sistema anterior, los comercializadores de último recurso (CUR) suministraban:

- A los consumidores a TUR, que en atención a determinados umbrales de tensión y de potencia contratada recibían su suministro al precio regulado de la TUR.

- A los consumidores vulnerables, personas físicas en su vivienda habitual a las que era de aplicación el bono social, al cumplir ciertas condiciones sociales y de consumo.

Con la Ley 24/2013, los llamados comercializadores de referencia suministran:

- A los consumidores a precio voluntario para el pequeño consumidor, o PVPC (tarifa regulada).

- A los consumidores vulnerables, que son los que cumplan determinadas características sociales y de poder adquisitivo, a quienes resulta de aplicación el bono social, el cual cubre la diferencia entre el señalado precio voluntario y un precio base al que la nueva regulación llama tarifa de último recurso.

Como en el sistema previo, los comercializadores libres suministran al resto de consumidores, al precio y condiciones libremente pactados.

Resulta así que la anterior TUR equivale al nuevo PVPC; el antiguo bono social se mantiene como mecanismo aplicable a consumidores vulnerables, los cuales pagan el precio de la nueva tarifa de último recurso (para consumidores vulnerables) y el anterior CUR pasa a llamarse comercializador de referencia CR.

${ }^{11}$ Véase el R. D. 216/2014, de 28 de marzo, por el que se establece el método de cálculo de los precios voluntarios para el pequeño consumidor de energía eléctrica y su régimen jurídico de contratación (BOE núm. 77 de 29 de marzo de 2016). 
De modo que la nueva LSE 24/2013 distingue:

\section{A) Precio voluntario para el pequeño consumidor (PVPC)}

Los precios voluntarios para el pequeño consumidor ${ }^{12}$ son los precios máximos que podrán cobrar los comercializadores de referencia a los consumidores que se acojan a dicho precio. Calculados conforme a la metodología establecida en el reglamento y fijados considerando la estructura de peajes de acceso y cargos en vigor en cada momento.

Podrán acogerse al PVPC los titulares de los puntos de suministro de baja tensión (no superior a $1 \mathrm{kV}$ ) y con potencia contratada menor o igual a $10 \mathrm{~kW}$. Los usuarios acogidos a PVPC son los herederos de la tarifa de último recurso en el marco de la Ley 54/1997, del Sector Eléctrico.

Conforme al artículo 17.2 de la Ley 24/2013, desarrollado por el artículo 6.2 del RD 216/2014, el PVPC está compuesto por los siguientes elementos:

- Coste de producción de la energía eléctrica. Las novedades introducidas por el RD 216/2014 afectan principalmente al método de determinación del coste de producción de energía eléctrica (cfr. art. 9 RD 216/2014).

- Peajes de acceso y cargos que correspondan. Con carácter general, y sin perjuicio de desajustes temporales que obliguen al regulador a intervenir, los peajes de acceso a las redes y los cargos destinados a financiar los costes del sistema se establecerán anualmente por el Ministro de Industria, Energía y Turismo, previo Acuerdo de la Comisión Delegada del Gobierno para Asuntos Económicos, con base en las estimaciones realizadas (art. 16 Ley 24/2013).

Mediante la Orden IET/107/2014, de 31 de enero, se revisan los peajes de acceso de energía eléctrica para 2014. Los peajes de acceso se componen de un término de potencia y de un término de energía. La Orden IET/107/2014 incrementa el precio del término de potencia contratada para todas las tarifas, reduce ligeramente el precio de la energía para las tarifas de menos de $15 \mathrm{~kW}$ contratados y lo aumenta, también, para el resto de tarifas.

12 José Luis Sancha Gonzalo, en Revista Anales de Mecánica y Electricidad. Septiembre-Octubre de 2014. 
- Costes de comercialización, que serán fijados por orden del Ministro de Industria, Energía y Turismo, previo Acuerdo de la Comisión Delegada del Gobierno para Asuntos Económicos.

PVPC = Peaje de acceso y cargos (regulado) + Coste horario de energía (mercado) + [Energía reactiva]

\section{B) Tarifas de último recurso (TUR)}

Las tarifas de último recurso se aplicarán a los siguientes colectivos:

- Consumidores que tengan la condición de vulnerables. Serán considerados como consumidores vulnerables los consumidores de electricidad que cumplan con las características sociales, de consumo y poder adquisitivo que se determinen y en todo caso, «se circunscribirá a personas físicas en su vivienda habitual» (art. 45.1 Ley 24/2013). El RD 216/2014 no precisa la definición de consumidores vulnerables. En este caso, la TUR será el resultado de aplicar al PVPC un descuento del 25 por ciento en todos los términos que lo componen.

TUR vulnerables $=$ PVPC $-25 \%$

Las condiciones contractuales aplicables a los consumidores que tengan la condición de vulnerables se regirán por lo establecido para los contratos de los consumidores acogidos al PVPC, no estando obligado el comercializador de referencia a facilitar el suministro en los casos de impago previstos en el artículo 4.2.

- Consumidores que, sin cumplir los requisitos para la aplicación del PVPC, transitoriamente no dispongan de un contrato de suministro en vigor con un comercializador en mercado libre. El precio será el resultado de aplicar un incremento del 20 por ciento sobre los términos de los peajes de acceso que correspondan al punto de suministro al que debe realizarse la facturación y al resto de términos que incluye el PVPC de acuerdo a lo previsto en el título III para el cálculo del PVPC correspondiente al consumidor con peaje de acceso sin discriminación horaria. El exceso que perciban los comercializadores de referencia sobre el PVPC tendrá la consideración de ingresos liquidables, debiendo el comercializador de referencia proceder a su abono al distribuidor.

TUR sin derecho a PVPC $=($ Peajes de acceso $+20 \%)+($ Resto términos PVPC peaje de acceso 2.0. A sin discriminación horaria $+20 \%$ ) 


\section{C) Bono social}

El bono social será de aplicará a los consumidores calificados como vulnerables que cumplan con las características sociales, de consumo y poder adquisitivo establecidos por reglamento ${ }^{13}$. A estos efectos, se establecerá un umbral referenciado a un indicador de renta per cápita familiar. En todo caso, se circunscribirá a personas físicas en su vivienda habitual. En el RD 216/2014 no se especifican las características de los usuarios beneficiarios del bono social.

Será la diferencia que resulte entre la facturación correspondiente al PVPC y la facturación a tarifa de último recurso.

\section{Bono social $=$ PVPC - TUR}

El bono social constituye una obligación de servicio público cuyo coste será asumido por las matrices de los grupos de sociedades o, en su caso, sociedades que desarrollen simultáneamente las actividades de producción, distribución y comercialización de energía eléctrica. La Orden IET/350/2014, de 7 de marzo, fija los porcentajes de reparto de las cantidades relativas al bono social correspondientes a 2014 a financiar por las matrices de los grupos de sociedades o, en su caso, sociedades, que desarrollan simultáneamente las actividades de producción, distribución y comercialización de energía eléctrica.

\section{NOVEDADES CONTRACTUALES}

\section{Regulación del contenido contractual}

El RD 216/2014 regula el contenido de los contratos de los comercializadores de referencia con los consumidores acogidos bien a PVPC, también los de TUR y bono social, y acogidos al sistema de ofertas anuales fijas.

Con carácter general, los contratos incluirán el acceso a la red, en cuyo caso, el comercializador de referencia contratará con el distribuidor el acceso a las redes en nombre del consumidor. No obstante, el usuario puede optar por contratar de forma separada la adquisición de la energía y el acceso a la red ${ }^{14}$.

El Reglamento se remite expresamente a lo establecido en la legislación de consumidores respecto a la entrega de la información pre-

${ }^{13}$ Art. 45.2 Ley 24/2013.

${ }^{14}$ Arts. 18.1. II RD 216/2014 y art. 46.1.d Ley 24/2013. 
contractual, especialmente en caso de contratación a distancia; la necesidad de claridad de los condiciones contractuales y la prohibición de cláusulas o prácticas que obstaculicen el ejercicio de derechos por los clientes (art. 18.5 RD 216/2014).

El contrato a PVPC o a precio fijo anual no incluirá ningún otro producto o servicio, sea energético o no, ofrecido directamente por el comercializador de referencia o por terceros.

El artículo 19 del RD 216/2014 destaca:

- La Referencia de la página web de la Comisión Nacional de los Mercados y la Competencia (CNMC) en la que figuran las ofertas comerciales anuales para colectivos de consumidores (arts 14.7.b y 19.1.d RD 216/2014).

Conforme a la jurisprudencia comunitaria (STJUE de 5 de julio de 2012, C 94/11), se ha de precisar que la referencia al enlace de la web en la que se encuentran las ofertas no debe sustituir a la información sobre la oferta realmente contratada incluida en la información previa al contrato y en el propio contrato. El artículo 20 impone obligaciones de información tanto a los comercializadores de referencia como a la propia CNMC.

No se establece la mismo obligación respecto a la web del operador del sistema (Red Eléctrica, www.ree.es), en la que se publicará diariamente el precio de la energía en el mercado mayorista, cambiante en función de la oferta y la demanda de cada hora y determinante del PVPC.

\section{Causas de rescisión y resolución, cláusulas de penalización y en particular, el derecho a la resolución unilateral del usuario acogido a PVPC (art. 19.1.f) Ley 24/2013}

El contrato ha de indicar expresamente las causas de rescisión y resolución del contrato «que sean sin coste para el consumidor, entre las que figurará, en el caso de que el consumidor esté acogido al precio voluntario para el pequeño consumidor, la de su derecho a resolver el contrato por voluntad unilateral del consumidor».

\section{Servicio gratuito de atención telefónica al cliente}

Por su parte, el artículo 19.1.h) exige que el contrato contenga «información sobre el servicio de atención a quejas, reclamaciones 
e incidencias en relación al servicio contratado u ofertado, así como solicitudes de información sobre los aspectos relativos a la contratación y suministro o comunicaciones». En concreto, deberá constar «la dirección postal, servicio de atención telefónica y número de teléfono, ambos gratuitos, y el número de fax o dirección de correo electrónico al que el consumidor pueda dirigirse directamente».

\section{Mecanismo de corrección de errores en la facturación como consecuencia de errores administrativos y de medida, delimitando claramente el alcance y las responsabilidades del comercializador y del distribuidor (art. 19.1.n RD 216/2014)}

Desde que se liberalizó el suministro eléctrico, la distribución de responsabilidades entre comercializadores y distribuidor ha sido una de las cuestiones que mayor confusión ha generado entre los usuarios.

\section{Duración de los contratos y prohibición de cláusulas de permanencia}

La duración de los contratos de suministro a PVPC será anual y se prorrogará automáticamente por plazos iguales. El comercializador de referencia deberá remitir al consumidor una comunicación, por escrito o cualquier medio en soporte duradero, con una antelación mínima de dos meses donde conste la fecha de finalización del contrato. En dicha comunicación, se indicará expresamente que si el consumidor no solicita un nuevo contrato, ya sea con el comercializador de referencia o con cualquier otro comercializador, a partir de la fecha de finalización le seguirá siendo de aplicación el PVPC con el mismo comercializador de referencia, indicando las condiciones del contrato correspondientes al mismo.

El consumidor podrá resolver el contrato antes de su finalización o de la finalización de cualquiera de sus prórrogas, «sin coste alguno».

Por contraposición con la regulación de las condiciones de los contratos sometidos a ofertas fijas anuales, en las que sí se admiten las «cláusulas de penalización» por incumplimiento de los periodos de permanencia, habrá que interpretar este «sin coste alguno» no solo en el sentido de que el procedimiento de baja voluntaria unilateral debe resultar gratuito para el usuario, sino también en el sentido de que se excluye cualquier penalización por baja anticipada. 


\section{Cambios de comercializador}

En caso de que la resolución del contrato tenga origen en un cambio de comercializador, el consumidor lo comunicará al comercializador entrante a efectos de que éste lo comunique al distribuidor que corresponda y se inicie el procedimiento de cambio de comercializador.

El plazo máximo para el cambio de comercializador de los consumidores con derecho a quedar acogidos será de 21 días, contados desde la recepción de la solicitud de cambio por el distribuidor, aunque en aquellos puntos de suministro en que no sea preciso realizar actuaciones sobre las instalaciones, el consumidor podrá optar por que el cambio de comercializador se haga dentro del plazo máximo de 15 días siguientes a la solicitud, cuando corresponda según ciclo de lectura o también en fecha elegida por él.

\section{REFLEXIONES CONCLUSIVAS: ANÁLISIS CRÍTICO DE LA REFORMA. INCIDENCIA EN LOS DERECHOS DE LOS DENOMINADOS CONSUMIDORES DOMÉSTICOS}

Con carácter previo, cabe afirmar que en la nueva regulación, las mejoras en la protección a los consumidores superan a las carencias. La Ley 24/2013, supone una clara mejora en la técnica jurídica y en el sistema de protección administrativa del consumidor. Sin embargo, la nueva normativa contiene importantes carencias pero también aciertos.

\section{Carencias o deficiencias en la protección de los derechos del consumidor}

A continuación describimos alguno de los defectos regulatorios que inciden en la órbita del consumidor doméstico:

a) En la definición del bono social, no se contiene ninguna indicación a la llamada "pobreza energética»

En efecto, la Directiva 2009/72/CE cede a los Estados la definición de consumidor vulnerable, y se limita a sugerir que «podrá referirse a la pobreza energética» (artículo 3.7).

La pobreza energética está definida en el Dictamen del Comité Económico y Social Europeo ${ }^{15}$ como, «la dificultad o la incapacidad

${ }^{15}$ DOUE C-44, de 11/02/2011, pág. 53. 
de mantener la vivienda en unas condiciones adecuadas de temperatura así como de disponer de otros servicios energéticos esenciales a un precio razonable». El legislador español, no se ha aventurado, si bien el ámbito subjetivo del bono social debería definirse considerando la pobreza energética.

En la «Diagnosis de las causas y de las consecuencias de pobreza energética en Bélgica, Francia, Italia, España y Reino Unido» ${ }^{16}$, no se oculta que "España registra uno de los niveles más altos de mortalidad en invierno en Europa...", algo relacionado con "niveles de pobreza, desigualdad económica, falta de calefacción u otras causas relacionadas con "vulnerabilidad al frío» » ${ }^{17}$; o que las causas de dicha pobreza son «los bajos ingresos, las pobres condiciones de la vivienda (por ejemplo, mal aislamiento), falta de sistemas de calefacción, subsidios por ingresos insuficientes, elevada pobreza y más del 50\% de la gente mayor viviendo en condiciones de pobreza» ${ }^{18}$.

El documento «Pobreza energética en España. Potencial de generación de empleo derivado de la rehabilitación energética de viviendas» de 2012, realizado en el marco del proyecto REPEX, señala: "Aunque no existe una herramienta que de forma directa mida la pobreza energética, se sabe que un porcentaje importante de la población española (probablemente más de un 10\%) la está sufriendo».

Así, la definición final del ámbito subjetivo del bono social queda pendiente de la aprobación del Real Decreto sobre actividad de comercialización. El proyecto de Real Decreto, objeto del Informe 25/2013 de la CNE, exige tener en cuenta el nivel de renta de la unidad familiar (la renta familiar no debe superar el 120\% del salario mínimo interprofesional para la primera persona, el 70\% para la segunda y el $50 \%$ para la tercera y siguientes), en combinación con el resto de criterios que se venían exigiendo, potencia contratada inferior a $3 \mathrm{~kW}$, pensionistas, familias numerosas y familias con todos sus miembros en situación de desempleo.

Considero, en este punto, que han pesado, en exceso, las razones políticas para abordar este problema de enorme calado y sensibilidad social que constituye, lamentablemente, una realidad en España y otros países de la Unión Europea en el actual contexto de crisis económica.

\footnotetext{
${ }^{16}$ Proyecto European Fuel Poverty and Energy Efficiency, elaborado en el marco del Espacio Europeo de Investigación.

${ }^{17}$ Pág. 38.

${ }^{18}$ Pág. 40.
} 
b) El procedimiento de cálculo del precio de la energía aprobado por Real Decreto 216/2014, de 28 de marzo, por el que se establece la metodología de cálculo de los precios voluntarios para el pequeño consumidor de energía eléctrica y su régimen jurídico de contratación

Este procedimiento resulta muy confuso y complejo para el consumidor doméstico, habiendo sido denunciado por asociaciones de consumidores el Gobierno español ante la Comisión Europea al considerar que el sistema vulnera hasta tres directivas comunitarias. No solo es discutible que sea eficaz como instrumento de reducción del precio de la energía, sino que adolece falta de transparencia, posibles tratamientos discriminatorios y una eventual determinación unilateral por el comercializador de elementos esenciales del contrato.

La exposición de motivos del RD 216/2014, indica que el nuevo modelo está construido desde la convicción de que producirá una reducción del precio de la energía, al descontar el coste de la seguridad que da el mercado a largo plazo. El Gobierno estima que en los últimos cinco años la seguridad ha tenido un coste adicional para el pequeño consumidor de 1.600 millones de euros. En definitiva que, renunciar a esta seguridad y optar por un modelo de precios sometido a la incertidumbre del mercado diario conllevará unos precios más reducidos.

Sin embargo, pese a las intenciones expuestas, no parece que este nuevo método conlleve a una reducción de la tarifa energética, pues resulta consustancial que el consumidor adopte decisiones conforme a la información publicada, lo que puede provocar el incremento de la demanda de electricidad real en aquellas horas en la que el precio diario sea más bajo, lo que a su vez provocará un incremento del precio en el mercado intradiario por el juego de la oferta y la demanda y sobre todo, en el precio de los servicios de ajuste del sistema se incrementará, al tener que acomodarse la generación a la demanda de energía. En definitiva, el precio de estos servicios de ajuste también acabará incorporado al precio final de la energía (art. 6.2.a RD 216/2014).

De otro lado, todos aquellos consumidores que no disponen de un contador inteligente integrado en un sistema de telegestión, no pagarán el precio real de la energía consumida en cada hora, sino un promedio calculado por el operador del sistema según la fórmula establecida reglamentariamente. Para estos consumidores resultará imposible determinar cuáles han sido las horas sometidas a cada uno de los precios, 
por lo que al conjunto de horas consumidas se aplica el promedio. En estos casos, el precio horario pierde su efectividad como señal que determina un uso más eficiente de la energía cuando es más barata.

c) Falta de transparencia de los precios minoristas de la energía

Es una cualidad, la de la transparencia, exigida tanto por la normativa sectorial como por la normativa general de consumo. Así, Directiva 2009/72/CE del Parlamento Europeo y del Consejo de 13 de julio de 2009 sobre normas comunes para el mercado interior de la electricidad exige que los Estados miembros garanticen el derecho al suministro de electricidad de una calidad determinada y a "unos precios razonables, fácil y claramente comparables, transparentes y no discriminatorios ${ }^{19}$.

El artículo 44 de la Ley 24/2013 reconoce a los consumidores el derecho a «ser suministrados a unos precios fácil y claramente comparables, transparentes y no discriminatorios» y a «recibir información transparente sobre los precios y condiciones generales aplicables al acceso y al suministro de energía eléctrica». Por su parte, la exposición de motivos del RD 216/2014 defiende que «este nuevo mecanismo permitirá lograr una mayor transparencia en la fijación del precio». Así, si se conocen a partir de las ocho y cuarto de la tarde del día anterior al consumo, los precios del mercado diario del día siguiente, el consumidor tomará sus decisiones de forma acorde con esa información.

Sin embargo, distinta es la obligación de transparencia, de la obligación de los comercializadores o de los diversos organismos públicos y privados implicados -Comisión Nacional de los Mercados y de la Competencia, el operador del sistema, el operador del mercado- de publicar en su web información técnica muy detallada sobre el precio de la energía. Transparencia es claridad y concisión en la información, empero, el nuevo sistema está sustentado en presupuestos equivocados al confundir transparencia y deber de información, lo que está dando lugar a un desconcierto generalizado de los consumidores en la nueva determinación del precio de la energía eléctrica, un desconocimiento del precio de la energía eléctrica por la complejidad del propio sistema de determinación e información.

En primer lugar, no todos los usuarios de energía eléctrica tienen acceso a internet y no se piensa en personas de avanzada edad que en

${ }^{19}$ Art. 3.3. 
condiciones de tener acceso a la red, no acostumbran, no pueden, o no están en condiciones de usar las nuevas tecnologías para estos cometidos. Aunque el índice de personas y hogares con acceso a la red es cada vez mayor, no cabe olvidar que todavía son millones los usuarios de energía eléctrica que carecen de este servicio y que nunca consultarán la web ni de Red Eléctrica de España (REE), ni de la Comisión Nacional de los Mercados y de la Competencia (CNME).

El anexo I del RD 216/2014, establece que la información que el operador del sistema (REE) ha de publicar en su web, es la relativa a los parámetros que determinan el precio final de la energía, resulta que ningún usuario medio va a comprender y por tanto, va a consultar una información que no entiende con sólo leer las Órdenes Ministeriales que establecen tales parámetros ${ }^{20}$.

\section{d) El deber de información}

Se considera que la formulación de éste resulta deficiente pues, el nuevo método hace recaer sobre el consumidor la carga de obtener la información sobre el precio de la energía y otras cuestiones asociadas que pueden llevarle a tomar sus decisiones de consumo.

Existen varios los supuestos en los que los deberes de información de los comercializadores se consideran agotados por el hecho de remitir información a la web de la CNMC, a la Agencia Española de Consumo, Seguridad Alimentaria y Nutrición (art. 20 RD 216/2014) y con la formulación de ofertas a precio fijo anual. En estos supuestos se impone a los usuarios la carga de consultar y comparar la información. Sólo un usuario especialmente diligencia acudirá a esos medios de información pero no, el usuario medio, la mayoría, asumirá esa carga impuesta ex legem (téngase en cuenta el segmento de población española de edad avanzada que no accederá a la red).

El contrato de suministro a PVPC, así regulado, se convierte en un contrato a precio variable, en el que el precio oscila según los condicionamientos y el funcionamiento del mercado diario de energía eléctrica. El consumidor queda a merced del comercializador de referencia, autorizándole a cobrar la energía al precio que resulte del mercado, con la suma de los peajes de acceso, regulados anualmente por el Ministerio de Industria, Energía y Turismo, y del precio de la energía durante cada hora de consumo, conforme a complejos parámetros y coeficientes fijados, calculados y publicados por el operador

${ }^{20}$ Véase, a título de ejemplo, el artículo 10 del RD 216/2012. 
del sistema, REE, bajo la supervisión de la Secretaría de Estado de Energía ${ }^{21}$.

El nuevo sistema tampoco se cohonesta con otras exigencias de información impuestas por el artículo 44.1.d) de la Ley 24/2013 que exige que el contrato de suministro especifique «la información actualizada sobre precios y tarifas aplicables y, en su caso, disposición oficial donde se fijen los mismos». Obviamente, el contrato de suministro a PVPC no puede contener esta información sobre los precios sujetos a las fluctuaciones del mercado, en todo caso, una referencia a la web donde se publiquen los elementos determinantes del PVPC. Sin embargo, los artículos 19 y 20 del RD 216/2014 sobre el contenido del contrato o los deberes de información no exigen incluir la referencia a la web de REE.

El artículo 44.1.e) reconoce el derecho de los usuarios a «ser notificados de forma directa por su suministrador sobre cualquier revisión de los precios derivada de las condiciones previstas en el contrato en el momento en que ésta se produzca, y no más tarde de un período de facturación después de que haya entrado en vigor dicha revisión, de forma transparente y comprensible». Esta exigencia legal también resulta incompatible con el funcionamiento del nuevo sistema, en el que los precios se modifican cada hora y las previsiones se publican a través de la web de REE apenas unas horas antes de su aplicación.

De tales preceptos, se desprende que la energía eléctrica como producto que es debería estar sujeto a unos precios ciertos y determinados previamente a la prestación del servicio y su puesta a disposición del consumidor -así resulta del articulado de la Ley 24/2013 en lo que se refiere a los derechos de los consumidores- en realidad parece que le faltó la previsión necesaria al legislador de 2013 para compatibilizar los derechos de los consumidores detallados en dicha Ley, con el nuevo procedimiento para la determinación del precio de la energía eléctrica conforme a lo dispuesto en el RD 216/2014. Así, muchos de los preceptos de esta última disposición, dejan vacíos de contenido las previsiones referentes a los derechos de los «consumidores domésticos», resulta insuficiente la obligación impuesta a los comercializadores de referencia de enviar a los consumidores acogidos a PVPC, con la primera factura emitida a partir del 15 de abril de 2014, el modelo contenido en el anexo II del reglamento para informar sobre el cambio de método ${ }^{22}$.

\footnotetext{
${ }^{21}$ Art. 7.8 RD 216/2014.

${ }^{22}$ DT $1 .{ }^{a} 5$.
} 
Conforme al artículo 5 de la Directiva 2011/83/UE del Parlamento Europeo y del Consejo, de 25 de octubre de 2011, sobre los Derechos de los Consumidores, el comercializador cumple sus deberes de información precontractual si informa sobre «la forma en que se determina el precio». El problema del nuevo sistema, radica en que la forma de determinación del precio es tan confusa -un precio distinto para la energía consumida cada hora del periodo de facturación- que la información no garantiza la decisión consciente. Lo anterior vulnera numerosos preceptos de la normativa de consumidores: 20.1.C, 60.1 y 60.2.c del Texto Refundido de la Ley General para la Defensa de los Consumidores y Usuarios (TRLGDCU) en redacción dada por la Ley $3 / 2014$, por la que se modifica el TRLGDCU y otras leyes complementarias, aprobado por el Real Decreto Legislativo 1/2007, de 16 de noviembre. Como se ha expuesto, las directivas comunitarias sectoriales no justifican esta reducción del nivel de protección, antes bien, obligan a que las tarifas sean transparentes y no discriminatorias.

e) El nuevo método de determinación del precio puede amparar tratamientos discriminatorios

La aplicación del precio real del mercado diario o del precio promedio según perfiles de consumo depende del tipo de equipo de medida, analógico o inteligente conectado a un sistema de telegestión.

Serán los distribuidores, los obligados a sustituir los contadores conforme a un plan de ejecución paulatina que culminará el 31 de diciembre de $2018^{23}$, pero tal decisión queda fuera del ámbito del consumidor doméstico, lo que podría calificarse como un tratamiento discriminatorio contrario a la normativa sectorial de no discriminación del artículo 3.3 de la Directiva 2009/72/CE y de los artículos 44.1.i) y j) de la Ley 24/2013.

f) El nuevo sistema parece incentivar a los consumidores a salir al mercado libre

El nuevo sistema parece incentivar a los consumidores a salir al mercado libre, buscando alternativas a precio fijo, cierto y conocido. Esta decisión no es en sí misma contraria a los derechos del consumidor, pero sí lo puede ser si el consumidor decide de forma inconsciente o no autónoma.

${ }^{23}$ Orden ITC/3860/2007. 
Sin embargo, hemos de tener en cuenta que las ofertas fijas conllevan plazos de permanencia y pueden incluir cláusulas de penalización por baja anticipada y las condiciones contractuales en el mercado son libremente negociadas entre consumidor y comercializador. Desde la perspectiva del Derecho de Consumo, cualquier elemento, el método de determinación del precio, que no garantice la libre decisión del consumidor podría vulnerar su normativa.

g) Existencia de dispersión normativa en lo relativo a las atribuciones competenciales en materia de protección de los consumidores

La Ley 3/2013, de 4 de junio, de creación de la Comisión Nacional de los Mercados y de la Competencia (CNMC) determina sus competencias en el sector energético y asigna al Ministerio de Industria, Energía y Turismo, (MINETUR) ciertas funciones atribuidas a la anterior Comisión Nacional de la Energía (CNE), como la atención de quejas de usuario. Así, las competencias sobre protección de consumidores se reparten ahora entre: a) la CNMC; b) el MINETUR; y c) las Comunidades Autónomas. Tal dispersión puede generar confusión y producir algunas ineficiencias ${ }^{24}$.

h) Ausencia de un modelo de contrato escrito para el suministro de referencia

Los consumidores a PVPC y a TUR cuentan con un régimen jurídico más intensamente regulado que los suministrados a puro mercado liberalizado. En su día, la CNE sugirió la plasmación por escrito de las nuevas condiciones contractuales ${ }^{25}$.

La existencia de un contrato escrito proporcionaría mayor seguridad jurídica a los clientes domésticos, pues aclararía su relación, tanto con el distribuidor a cuya red se conecta, como con el comercializador

${ }^{24}$ Estoa Pérez, Abel, «Liberalización del suministro y desprotección del consumidor doméstico» Revista Española de Derecho Administrativo, 2013, núm. 193.

25 «Informe 34/2008, de 2 de diciembre de 2008, sobre la propuesta de Real Decreto por el que se regula la puesta en marcha del suministro de último recurso en el sector de la energía eléctrica»; o "Informe sobre el sector energético español. Parte V», de 7 de marzo de 2012, pág. 28), pág. 34; «Informe 13/2009, de 27 de mayo de 2009, sobre la Propuesta de Orden por la que se establece el mecanismo de traspaso de clientes del mercado a tarifa al suministro de último recurso, en especial, anexo I» o "Informe sobre el sector energético español. Parte V», de 7 de marzo de 2012, pág. 28. 
que le suministra la energía, toda vez que en la práctica, el consumidor de referencia solo mantiene contacto con el comercializador. Téngase en cuenta que la contratación del suministro lleva implícita la contratación del acceso a la red, incluyendo el PVPC y la TUR los peajes de acceso (precio por el uso de las redes y otros costes regulados que recauda el comercializador y paga al distribuidor, a fin de que éste lo declare al sistema de liquidación de ingresos y costes regulados).

\section{i) La atención al cliente}

Establece el anexo I de la Directiva 2009/72/CE que en los contratos con los consumidores domésticos figuren «los acuerdos de compensación y reembolso aplicables si no se cumplen los niveles de calidad contratados, incluida la facturación incorrecta y retrasada». Por su parte, el artículo 51 de la Ley 24/2013, define la calidad del suministro eléctrico como «el conjunto de características, técnicas y de atención y relación con los consumidores y, en su caso, productores, exigibles al suministro de electricidad de las empresas que realicen actividades destinadas al suministro eléctrico». La calidad de atención al consumidor se refiere «al conjunto de actuaciones de información, asesoramiento, estudios de acceso, conexión, medida, contratación, facturación, comunicación y reclamación».

De la lectura de tales preceptos se infiere, que la calidad es un concepto amplio que incluye tanto aspectos técnicos como comerciales; y afecta tanto a empresas distribuidoras como empresas comercializadoras libres o de referencia. Y ello porque la Ley se refiere, sin exceptuar a ninguna, a las «empresas que realicen actividades destinadas al suministro».

\section{Mejoras en el nivel de protección al consumidor}

a) Concentración normativa

La protección a los consumidores, dispersa en distintas normas, acumuladas sucesivamente de forma poco coherente, sin que unas sustituyesen a las anteriores, como procedería en buena técnica normativa. Dicha regulación había devenido obsoleta. La principal norma reguladora del suministro, el Real Decreto 1955/2000, acometía sin reformas sustanciales del antiguo sistema a tarifa integral por los distribuidores. La aplicación de ese Real Decreto al suministro liberalizado que sucedió a la antigua tarifa integral debía hacerse por ana- 
logía. Pero las piezas no encajaban bien, ambos sistemas eran escasamente conciliables entre sí. Además, era una regulación incompleta, con graves consecuencias para los consumidores, porque no se habían transpuesto los derechos reconocidos en el anexo I de la Directiva 2009/72/CE.

Como hemos dicho, la Ley 24/2013 regula el suministro a PVPC y a TUR para consumidores vulnerables. El Real Decreto-ley 13/2012, de transposición de las Directivas de 2009 sobre los mercados eléctrico y gasista, no incorporó el anexo I de la Directiva 2009/72/CE a la anterior Ley 54/1997, aunque sí transpuso íntegramente el análogo anexo I de la Directiva 2009/73/CE (mercado gasista) a la Ley 34/1998, de 7 de octubre, del sector de hidrocarburos (nuevo art. 57 bis).

Esa omisión se remedia ahora. Los consumidores de energía eléctrica ven así reconocido el elenco completo de derechos del citado anexo I, derecho indisponible para las partes que suscriban un contrato de suministro de electricidad. La novedad se incluye en el artículo 44 de la LSE 24/2013.

b) Nuevo sistema de protección en vía administrativa

La Directiva 2009/72/CE exige procedimientos de resolución de reclamaciones rápidos, eficaces; transparentes, sencillos y poco onerosos; y que garanticen un nivel elevado de protección. Añade que los Estados garantizarán la existencia de un mecanismo independiente de resolución extrajudicial. El regulador ha de contribuir a la protección de los consumidores, sin perjuicio de las competencias de otras autoridades. Los derechos que los consumidores pueden alegar son, fundamentalmente, los del anexo I de la Directiva mencionada. Ante el Derecho de la Unión Europea el legislador español debe diseñar el nuevo mecanismo de atención a reclamaciones de particulares.

El régimen jurídico de este último puede resumirse del siguiente modo: Atendiendo a la Directiva 2002/22/CE (Directiva del servicio universal) y en el artículo 149.1.21. ${ }^{\mathrm{a}}$ de la Constitución (competencia exclusiva del Estado en materia de telecomunicaciones), fue promulgada la Ley 32/2003, cuyo artículo 38 dispone que el Ministerio de Industria, Energía y Turismo (MINETUR) establecerá reglamentariamente un procedimiento de resolución de controversias como alternativa a las juntas arbitrales de consumo. Ese desarrollo reglamentario figura en el Real Decreto 899/2009, de 22 de mayo (Carta de derechos 
del usuario de los servicios de comunicaciones electrónicas), y en la Orden ITC/1030/ 2007.

Lo anterior se ha reproducido para el sector eléctrico. Fundado en la normativa de la Unión Europea, la Ley establece los aspectos generales de un mecanismo de resolución de controversias, a desarrollar mediante orden. Dicha regulación consta en los apartados 4 a 6 del artículo 43 de la Ley 24/2013. El artículo 43.4 de la Ley 24/2013 contiene una referencia a sistemas propios de las compañías eléctricas y a la vía arbitral de consumo en sede autonómica como posibles medios de resolución de discrepancias.

En defecto de los anteriores, cabría acudir al nuevo sistema, cuya regulación sustancial figura en el apartado 5 del artículo 43 de la Ley 24/2013. El primer párrafo de dicho artículo 43.5 define los ámbitos subjetivo y objetivo. El segundo remite a desarrollo reglamentario. El tercero se refiere al sometimiento obligatorio al procedimiento y a la resolución del mismo. El último párrafo aclara que el sistema se aplica a todas las modalidades de suministro que la Ley regula.

El artículo 43 dispone en su párrafo $1 .^{\circ}$ : Para el supuesto de que no se sometan a las entidades de resolución alternativa de litigios en materia de consumo o que estas no resulten competentes... los usuarios finales que sean personas físicas podrán someter la controversia al Ministerio de Industria, Energía y Turismo, cuando tales controversias se refieran a sus derechos específicos como usuarios finales, incluidos todos los previstos en esta ley y sin perjuicio de las competencias del resto de Administraciones Públicas. No podrán ser objeto del procedimiento anterior las controversias que se encuentren reguladas por normativa distinta de la de protección específica de los usuarios finales de energía eléctrica.

El párrafo $2{ }^{\circ}$ prevé: «El procedimiento, que se aprobará por orden del Ministro de Industria, Energía y Turismo, deberá ser transparente, sencillo y gratuito. La resolución que se dicte podrá ordenar la devolución de importes indebidamente facturados y, en general, disponer cuantas medidas tiendan a restituir al interesado en sus derechos e intereses legítimos, incluyendo la posibilidad de reembolso y compensación por los gastos y perjuicios que se hubiesen podido generar».

Su párrafo $3 .^{\circ}$ establece: «Los sujetos del sector eléctrico estarán obligados a someterse al procedimiento, así como a cumplir la resolución que le ponga fin. En cualquier caso, el procedimiento que se adopte establecerá el plazo máximo en el que deberá notificarse la resolución expresa, transcurrido el cual se podrá entender desestima- 
da la reclamación... La resolución que se dicte podrá impugnarse ante la jurisdicción contencioso-administrativa».

El párrafo cuarto, por su parte, determina: «Lo dispuesto en este apartado será aplicable a todas las modalidades de suministro previstas en esta ley para usuarios finales que sean personas físicas».

Procede una breve explicación de este nuevo procedimiento:

- Habrá lugar a esta vía caso de no acudirse a otras entidades de resolución alternativa de litigios. Las entidades de resolución alternativa de litigios (ADR, en su acrónimo inglés) son entidades extrajudiciales de carácter neutral (conciliador, mediador, árbitro, defensor del consumidor, oficina de reclamaciones, etc.) que proponen, imponen o reúnen a las partes para encontrar una solución. Se regulan en la Directiva 2013/11/UE (cuya fecha de transposición finaliza el 9 de julio de 2015). El Consejo Europeo de Reguladores Energéticos (CEER) fomenta su implantación en el mercado europeo de la electricidad. El artículo 46.1.n) de la Ley incluye entre las obligaciones de las comercializadoras poner a disposición de los clientes la solución de conflictos a través de una entidad de ADR.

- El ámbito subjetivo comprende a «usuarios finales que sean personas físicas». Dicho ámbito, como sucede en telecomunicaciones, excluye la acción administrativa para las personas jurídicas. Se trata de un ámbito algo mayor que el de los usuarios domésticos, pues puede extenderse a profesionales. La exclusión de las empresas parece razonable. De ellas se espera tanto una mejor posición negociadora como una mejor situación para acudir a la vía judicial, salvo, tal vez, el caso de empresas muy pequeñas.

- Las reclamaciones deben limitarse a los derechos de los usuarios, «incluidos todos los previstos en esta ley». En vista de que la Ley incorpora el listado de derechos del anexo I de la Directiva 2009/72/CE, los consumidores domésticos cuentan con una protección adecuada.

- Los consumidores podrán someter la controversia al Ministerio «sin perjuicio de las competencias del resto de Administraciones Públicas». Este último inciso debe interpretarse en el sentido de que la vía administrativa estatal coexiste con la autonómica. Ello parece fundamentarse en una competencia concurrente del Estado y Comunidades Autónomas en materia de consumo. En este punto, la Ley es más expeditiva que el 
comentado Real Decreto-ley 13/2012, más cauto al abordar las cuestiones competenciales.

La Sentencia del Tribunal Constitucional 31/2010, sobre la calificación como "exclusiva» de la competencia autonómica en materia de consumo contenida en el artículo 123 del Estatuto de Autonomía de Cataluña, afirmaba acerca de la concurrencia existente: "La materia de defensa de consumidores es un ámbito de concurrencia competencial de títulos habilitantes diferentes de manera que... las competencias reservadas por la Constitución al Estado... se proyectarán cuando materialmente corresponda ${ }^{26}$. Así, declaró la constitucionalidad del precepto pues «en modo alguno es exigible la salvaguardia por el precepto estatutario de las competencias estatales concurrentes».

- No podrán someterse a dicha vía, controversias reguladas por normativa distinta de la de protección específica de los usuarios finales de energía eléctrica. Con ello evita el uso inadecuado de la vía administrativa, por ejemplo, mediante reclamaciones que correspondan exclusivamente a la vía judicial.

- El procedimiento, que se aprobará por Orden Ministerial, será transparente, sencillo y gratuito. El desarrollo reglamentario, aún pendiente, deberá ajustarse a las exigencias de transparencia, sencillez y gratuidad que proceden del Derecho de la Unión ${ }^{27}$.

- La resolución podrá ordenar la devolución de importes indebidamente facturados y, en general, disponer cuantas medidas tiendan a restituir al interesado en sus derechos e intereses legítimos, incluyendo el reembolso y compensación por los gastos y perjuicios que se hubiesen podido generar. Se trata de la incorporación del sistema de «reembolso y/o compensación» que señala la letra f) del anexo I de la Directiva 2009/ 72/ CE64. La transposición realizada permite no solo el reembolso o devolución de importes indebidamente facturados y la restitución del consumidor en sus derechos e intereses legítimos, sin cerrar el elenco de posibles decisiones, sino también la compensación por "gastos y perjuicios», lo que incluiría gastos de gestión (llamadas, burofaxes, correo postal, etc.).

${ }^{26}$ (FJ 70).

${ }^{27}$ Letra f) del anexo I de la Directiva 2009/72/CE. 
- El procedimiento es vinculante para los sujetos del sector eléctrico, que estarán obligados a someterse a él y a cumplir la resolución que le ponga fin. Con ello se configura como una vía bien distinta al arbitraje de consumo, voluntario para los operadores a tenor del TRLDCU.

- El silencio administrativo tendrá sentido negativo. Y la resolución que se dicte podrá impugnarse ante la jurisdicción contencioso-administrativa. Por tanto, la resolución que pone fin al procedimiento de resolución de discrepancias es recurrible en vía contenciosa. Ello constituye una diferencia con la vía arbitral de consumo, pues el laudo que pone fin al procedimiento arbitral no es recurrible con carácter general ${ }^{28}$.

- Todos los consumidores domésticos (usuarios finales personas físicas, en los términos de la Ley) disponen de acción en vía administrativa, con independencia de que se suministren a PVPC, a TUR o a mercado libre. Para que así suceda, todo consumidor doméstico debe contar con idéntica protección. Y un aspecto esencial de dicha tutela, consiste en que todos los consumidores dispongan de acceso a una vía extrajudicial de solución de conflictos rápida, gratuita y transparente. De ahí la valoración positiva de la nueva Ley en este punto.

- Por último, el apartado 6 del artículo 43 encomienda a la CNMC la supervisión de la efectividad y la aplicación de las medidas de protección a los consumidores, así como la facultad de dictar resoluciones jurídicamente vinculantes tendentes al cumplimiento de las mismas.

Por último cabe señalar, que el método puede resultar incompatible con la letra l del Anexo de la Directiva 93/13/CE sobre cláusulas abusivas en los contratos celebrados con consumidores (transpuesto al ordenamiento español por el art. 87. 10 TRLGDCU), según el cual se considerarán abusivas las cláusulas que tengan por objeto «estipular que el precio de las mercancías se determine en el momento de su entrega, u otorgar al vendedor de mercancías o al proveedor de servicios el derecho a aumentar los precios, sin que en ambos casos el consumidor tenga el correspondiente derecho a rescindir el contrato si el precio final resultare muy superior al precio convenido al celebrar el contrato». Si bien, se reserva a otros trabajos la profundización en este punto.

\footnotetext{
${ }^{28}$ Artículo 48 del Real Decreto 231/2008, de 15 de febrero, por el que se regula el Sistema Arbitral de Consumo, en relación con el art. 43 de la Ley 60/2003, de 23 de diciembre, de Arbitraje.
} 


\section{BIBLIOGRAFÍA}

ESTOA PÉREZ, Abel (2013), Liberalización del suministro y desprotección del consumidor doméstico», Revista Española de Derecho Administrativo, núm. 193.

FERNÁNDEZ DÍEZ, Isabel (2009), «Calidad del Suministro y derechos de los usuarios. La suspensión del suministro. Gestión de la demanda, ahorro y eficiencia energética», en Derecho de la Regulación Económica. III. Sector Energético. Tomo II, Iustel, Madrid, pag. 814.

LASARTE ÁLVAREZ, Carlos (2015), Manual sobre protección de consumidores y usuarios, Dykinson, Madrid, 7. ${ }^{\mathrm{a}} \mathrm{ed}$.

SANCHA GONZALO, José Luis (2014), Revista Anales de Mecánica y Electricidad. Septiembre.

VV. AA. (2014), Energía Eléctrica. Manual Básico para juristas, Dirs. Miguel Agúndez y Julián Martínea Simancas. La Ley.

ZURUTUZUA ARIGITIA, Iñaki (2013), «Perspectiva comunitaria, estatal y autonómica del concepto de consumidor», Revista doctrinal de Aranzadi Civil-Mercantil, núm. 6.

\section{Otras referencias}

Manual de Energía y Sociedad. Plataforma digital www.energíaysociedad.com integrado en el Campus Iberdrola. 